\title{
Inibição do Desenvolvimento Inicial de Plantas de Girassol, Milho e Triticale por Palhada de Capim-Colchão ${ }^{1}$
}

\author{
Inhibition of the Initial Development of Sunflower, Corn and Triticale Plants by Crabgrass
}

\author{
PEREIRA, M.R.R. ${ }^{2}$, TEIXEIRA, R.N. ${ }^{3}$, SOUZA, G.S.F. ${ }^{3}$, SILVA, J.I.C. ${ }^{4}$ e MARTINS, D. ${ }^{5}$
}

\begin{abstract}
RESUMO - O objetivo deste estudo foi avaliar os possiveis efeitos alelopáticos da massa seca de plantas de capim-colchão (Digitaria horizontalis), incorporadas ao solo em diferentes densidades, sobre a germinação e o crescimento inicial de milho, girassol e triticale. O experimento foi realizado em casa de vegetação, e as parcelas foram constituídas de uma planta, conduzida em vasos com capacidade para $2,5 \mathrm{~L}$, dispostos inteiramente ao acaso. Material seco de capim-colchão nas quantidades equivalentes a $0,2,5,5,0$ e 10 t ha $^{-1}$ foi incorporado à terra. A emergência foi avaliada diariamente até 10 dias após a semeadura, quando se calculou a porcentagem final de emergência e o índice de velocidade de emergência (IVE). A altura e a massa seca das plantas foram avaliadas 35 dias após a semeadura. A incorporação da palhada da planta daninha não interferiu na germinação e no IVE das espécies avaliadas. A massa seca e a altura de plantas de todas as espécies foram influenciadas pela palhada, decrescendo de acordo com o aumento da concentração da palhada incorporada ao solo, com exceção do triticale, que não teve alteração quanto à altura.
\end{abstract}

Palavras-chave: aleloquímicos, germinação, crescimento, capim-colchão.

ABSTRACT - The aim of this study was to evaluate the allelopathic effects of the dry mass of plants of crabgrass (Digitaria horizontalis), incorporated into the soil at different densities, on the germination and early growth of corn, sunflower and triticale. The experiment was conducted in a greenhouse, and the plots consisted of a plant, in pots with a capacity of $2.5 \mathrm{~L}$, arranged in a completely randomized design. Dry material of crabgrass in amounts equivalent to 0, 2.5, 5.0 and $10 t$ ha-1 was incorporated into the soil. Emergence was checked daily until ten days after sowing, when the final percentage of emergence and emergence speed index were calculated. Plant height and dry weight were evaluated 35 days after sowing. Weed germination residue incorporation and emergence speed index were found to interfere in the species evaluated. Dry weight and plant height of all species were affected by the crop residues, decreasing according to the concentration of straw incorporated into soil, with the exception of triticale, whose height remained unchanged.

Keywords: allelochemicals, germination, growth, crabgrass

\section{INTRODUÇÃO}

A alelopatia tem sido reconhecida como um importante mecanismo ecológico que influencia a dominância vegetal, a sucessão, a formação de comunidades vegetais e de vegetação clímax, bem como a produtividade e o manejo de culturas (Miró et al., 1998). É um mecanismo químico de liberação de metabólitos secundários por uma espécie de planta que afeta o crescimento ou a reprodução de outra planta. As substâncias alelopáticas podem ser produzidas em qualquer estrutura da planta durante o seu ciclo de vida. As concentrações apresentam variações inter e intraespecífica, que dependem da estrutura

Recebido para publicação em 27.6.2010 e na forma revisada em 6.5.2011.

2 Doutora em Agronomia, Pós-Doutoranda, Faculdade de Ciências Agronômicas, Universidade Estadual Paulista "Júlio de Mesquita Filho" - FCA/UNESP, Caixa Postal 237, 18603-970 Botucatu-SP, <mariarenata10@ hotmail.com>; ${ }^{3}$ Doutorando(a) em Agronomia/ Agricultura, FCA/UNESP, Botucatu-SP; ${ }^{4}$ Pós-Doutorando em Agronomia, Universidade Federal do Tocantins - UFT, Gurupi-TO; ${ }^{5}$ Professor, Adjunto do Dep. de Produção Vegetal, FCA/Unesp. 
vegetal e de seu estádio de desenvolvimento. Quando liberadas em quantidades suficientes, as substâncias podem causar inibição ou estimulação (dependendo da concentração) da germinação, crescimento e/ou desenvolvimento de plantas já estabelecidas e, ainda, o desenvolvimento de microrganismos (Souza Filho et al., 1997).

Segundo Putnam \& Tang (1987), quando uma planta daninha libera substâncias químicas no meio, reduzindo o desenvolvimento de outra ou de indivíduos da mesma espécie, temse a alelopatia.

A diminuição da produtividade causada por plantas invasoras ou resíduos de culturas anteriores pode ser resultado dos efeitos alelopáticos. Diversas plantas daninhas também podem ter seu desenvolvimento afetado por esses efeitos causados por outras plantas, como demonstrado em estudo realizado por Prates et al. (2003). Esses autores observaram redução da população de Brachiaria decumbens, Portulaca oleracea, Bidens pilosa e Amaranthus hibridus com a incorporação ou adição na superficie do solo da parte aérea de leucena, devido à liberação para o solo de substâncias com ação alelopática.

Em condições de plantio direto, a quantidade de palha que permanece sobre o solo interfere na intensidade do efeito alelopático. Quanto maior a quantidade mantida sobre o solo, mais substâncias alelopatas ela pode conter, maior quantidade pode ser lixiviada para o solo e maior a sua influência sobre as infestantes. Entretanto, apenas um grande volume de palha sobre o solo não é suficiente para suprimir uma população de daninhas, pois é necessário que esta contenha aleloquímicos tóxicos para as espécies presentes na área e que estes sejam liberados em concentração adequada (Almeida, 1991).

Quimicamente, a palhada da cobertura pode liberar substâncias no meio, que podem causar diminuição da germinação e do desenvolvimento de plantas daninhas (Goldfarb et al., 2009). Em um estudo do potencial alelopático de Cyperus rotundus sobre espécies cultivadas, Andrade et al. (2009) observaram efeitos alelopáticos tanto na germinação quanto no crescimento da plântula, sendo mais pronunciado no crescimento inicial do que sobre a germinação. Esse fato pode estar relacionado à absorção pelo sistema radicular, pois esta foi a estrutura vegetal que mais sofreu o efeito do extrato aquoso de folhas secas dessa espécie de planta daninha. As alterações nos padrões de germinação podem ser bastante estudadas, embora em alguns casos não demonstre diferenças significativas, já que envolve apenas resultados finais, ignorando períodos de germinação inativa (Chiapuso et al., 1997).

Os pesquisadores Hall \& Henderlong (1989) observaram que plantas de alfafa contêm compostos fitotóxicos solúveis em água que podem ser liberados no ambiente do solo por meio de exsudação de compostos de medicarpina em folhas frescas, caules, bem como de material seco, raízes em decomposição e sementes. O efeito alelopático ocorre quando substâncias fitotóxicas são liberadas pela lixiviação e exsudação das raízes e decomposição de resíduos de algum tipo de planta sobre a germinação das sementes e o crescimento de outras plantas (Nuñez et al., 2006). As substâncias alelopáticas liberadas por uma planta podem alterar o crescimento, prejudicar o desenvolvimento normal e até mesmo inibir a germinação das sementes de outras espécies vegetais (Weir et al., 2004).

O presente estudo teve por objetivo avaliar os possiveis efeitos inibitórios de diferentes concentrações de massa seca de Digitaria horizontalis sobre a germinação e o crescimento inicial de plantas de milho, girassol e triticale.

\section{MATERIAL E MÉTODOS}

Foram realizados três experimentos durante os meses de julho e agosto de 2009, no município de Botucatu-SP, em condições de casa de vegetação climatizada, com temperatura média de $26{ }^{\circ} \mathrm{C}$, sendo um para cada espécie estudada (milho, girassol e triticale).

O solo utilizado foi classificado de acordo com o novo Sistema Brasileiro de Classificação de Solos (Embrapa, 1999) e denominado de Latossolo Vermelho distrófico típico de textura média (46,5\% de argila, $14,5 \%$ de silte e $39 \%$ de areia), cuja análise química é apresentada na Tabela 1. Ele foi seco à sombra, peneirado 
Tabela 1 - Análise química do solo. Botucatu-SP, 2009

\begin{tabular}{|c|c|c|c|c|c|c|c|c|c|c|}
\hline $\mathrm{pH}$ & $\mathrm{MO}$ & $\mathrm{P}_{\text {resina }}$ & $\mathrm{Al}^{3+}$ & $\mathrm{H}+\mathrm{Al}$ & $\mathrm{K}$ & $\mathrm{Ca}$ & $\mathrm{Mg}$ & $\mathrm{SB}$ & $\mathrm{CTC}$ & $\mathrm{V} \%$ \\
\hline$\left(\mathrm{CaCl}_{2}\right)$ & \multicolumn{2}{|c|}{$\left(\mathrm{g} \mathrm{dm}^{-3}\right)$} & \multicolumn{7}{|c|}{$\left(\mathrm{mmol}_{\mathrm{c}} \mathrm{dm}^{-3}\right)$} & \\
\hline 4,8 & 20 & 37 & --- & 40 & 3,1 & 19 & 5 & 27 & 67 & 40 \\
\hline
\end{tabular}

em malha de $5 \mathrm{~mm}$ e adubado de acordo com as necessidades preconizadas pela análise química. Em razão da baixa fertilidade natural do solo, foi feita correção com calcário dolomítico com PRNT igual a 91\%. Empregou-se o método de saturação por bases (V\%) (Raij et al., 1997) para o cálculo de necessidade de calagem, visando aumentá-la para $70 \%$. O calcário foi misturado homogeneamente com o solo, que foi deixado em incubação úmida a aproximadamente $60 \%$ da capacidade de retenção de água por 30 dias. Cada repetição, de cada experimento, constou de um vaso plástico com capacidade para $2,5 \mathrm{~L}$, que foram irrigados diariamente. Em 5/7/2009, 10 sementes de milho, girassol e triticale foram semeadas na profundidade de $2 \mathrm{~cm}$. Os vasos foram dispostos inteiramente ao acaso com quatro repetições. Os tratamentos foram constituídos de quatro densidades de massa seca de plantas de capim-colchão, correspondentes a $0,2,5,5,0$ e $10 \mathrm{t} \mathrm{ha}^{-1}$, incorporadas ao solo. O solo de cada vaso foi misturado individualmente à palhada de forma manual e homogênea. A palhada de capim-colchão utilizada foi coletada em área experimental dentro do próprio campus e seca em estufa de circulação forçada de ar, a $45^{\circ} \mathrm{C}$ por 72 horas, sendo posteriormente triturada em moinho com malha de $0,3 \mathrm{~mm}$.

Os experimentos foram conduzidos por 35 dias, a partir da semeadura das espécies. Foram realizadas contagens diárias da emergência das plântulas até o décimo dia após a semeadura, e o IVE (indice de velocidade de emergência) foi calculado. Ao final das contagens diárias foi realizado desbaste das plântulas emergidas, mantendo-se uma planta por vaso. Ao final do experimento foi avaliada a altura de plantas, e a massa seca das espécies foi obtida com auxilio de uma estufa de circulação forçada de ar, a $60{ }^{\circ} \mathrm{C}$, por 72 horas.

Os resultados encontrados foram submetidos à análise de variância pelo teste $\mathrm{F}$ a $5 \%$ de probabilidade. Os dados de porcentagem de germinação e IVE tiveram as médias comparadas pelo teste de Tukey, e as equações de regressão foram ajustadas para os dados de massa seca e altura pelo programa Sisvar, sendo adotados os modelos de regressão linear e polinomial.

\section{RESULTADOS E DISCUSSÃO}

Nos três experimentos realizados, observou-se que as diferentes densidades de massa seca de capim-colchão não afetaram a emergência de plantas das três espécies avaliadas, bem como o IVE (Tabela 2). De acordo com Olibone et al. (2006), as substâncias químicas liberadas pelos resíduos vegetais deixados sobre a superficie do solo, como o observado no sistema de semeadura direta, têm comportamento diferenciado em relação ao que ocorre pelo método de incorporação. Neste, a massa seca fica distribuída no perfil do solo na profundidade em que foram incorporadas, sendo suas substâncias tóxicas mais rapidamente degradadas; já na semeadura direta estas se mantêm na camada superficial. Dessa forma, como a intensidade dos efeitos alelopáticos depende da concentração dos aleloquímicos, a sua ação é mais pronunciada na semeadura direta. Em estudo realizado por Maciel et al. (2003), a palhada da planta daninha capim-braquiária também não influenciou no IVE de sementes de amendoim-bravo. Esse fato pode ser explicado por estudo de Ferreira \& Aquila (2000), os quais relatam que a germinação é menos sensivel aos aleloquímicos do que o crescimento da plântula, pois as substâncias alelopáticas podem induzir o aparecimento de plântulas anormais, sendo a necrose da radicula um dos sintomas mais comuns. A germinação de sementes de milho não foi influenciada por extratos de colza, milheto, nabo, trigo e aveia, independentemente da concentração utilizada, as quais 
foram superiores a $80 \%$ - resultado este semelhante ao do tratamento testemunha (Tokura \& Nóbrega, 2005).

Segundo Correia et al. (2005), quando o efeito de extratos no desenvolvimento de plântulas é avaliado em placas de Petri ou gerbox, observa-se que o sistema radicular é mais afetado que a parte aérea, pois a absorção e a concentração de fitotoxinas são favorecidas nesse tecido, devido ao maior contato entre a radícula e o papel-filtro. Entretanto, esses autores relatam que, por vezes, não é observada inibição na germinação das sementes. Nesses casos, o sítio de ação do fitoquímico pode não estar relacionado à inibição da divisão celular do eixo embrionário, o que resulta na ausência de efeito sobre a germinação de sementes. Dessa forma, a bioatividade de extratos aquosos estaria condicionada à capacidade de absorção, translocação e mecanismo de ação dos seus compostos potencialmente inibitórios. Resultados diferentes foram obtidos por Oracz et al. (2007). Esses autores, avaliando a germinação de sementes de mostarda, observaram que o extrato aquoso de folhas de girassol inibiu em mais de $80 \%$ e também causou drástica redução da viabilidade das sementes. A redução na taxa de germinação também foi verificada por Isfahan \& Shariati (2007) em sementes de Coronilla varia quando submetidas aos extratos aquosos de Eucalyptus camaldulensis e Juglans regia.

Os tratamentos com diferentes concentrações de massa seca de capim-colchão reduziram linearmente a massa seca de todas as espécies estudadas, sendo essa relação diretamente proporcional: quanto maior a concentração incorporada ao solo, menor a massa seca das plantas (Figura 1).

Com a incorporação no solo de $2,5 \mathrm{t} \mathrm{ha}^{-1}$, observou-se pequeno incremento $(1,72 \%)$ na massa seca do triticale em comparação à testemunha, enquanto para o milho e o girassol verificou-se redução de 8,7 e 9,2\%, respectivamente. Quando foram adicionados 5,0 $\mathrm{t} \mathrm{ha}^{-1}$, o milho apresentou-se mais sensivel aos agentes inibitórios, tendo redução de massa seca de $28,6 \%$. As massas secas das plantas de girassol foram reduzidas em 19,9\%, e as de triticale, em apenas $12,5 \%$, sendo esta a espécie menos influenciada neste tratamento. Incorporando $10 \mathrm{t} \mathrm{ha}^{-1}$ no solo, verificou-se redução no desenvolvimento para todas as espécies estudadas. Foi observada redução de $33,3 \%$ para o milho, $33,2 \%$ para o girassol e $30 \%$ para o triticale, em relação às respectivas testemunhas. De acordo com Maciel et al. (2003), a incorporação de $6 \mathrm{t} \mathrm{ha}^{-1}$ de palhada de $B$. decumbens ao solo reduziu significativamente a massa seca de plantas de soja.

Na Figura 2, pode-se observar que a incorporação de massa seca de capim-colchão não afetou o desenvolvimento do triticale, não reduzindo a altura de suas plantas. $O$ menor efeito inibitório nessa variável devese à menor área foliar e espessura de folhas das plantas, o que resultou em menores massas secas quando as plantas foram submetidas aos diferentes tratamentos.

Tabela 2 - Porcentagem de emergência e índice de velocidade de emergência de sementes de milho, triticale e girassol semeadas em solo com diferentes concentrações de massa seca de capim-colchão. Botucatu-SP, 2009

\begin{tabular}{|c|c|c|c|c|c|c|}
\hline \multirow{2}{*}{$\begin{array}{c}\text { Concentração } \\
\left(\mathrm{t} \mathrm{ha}^{-1}\right)\end{array}$} & \multicolumn{3}{|c|}{ Emergência (\%) } & \multicolumn{3}{c|}{ IVE } \\
\cline { 2 - 7 } & Milho & Triticale & Girassol & Milho & Triticale & Girassol \\
\hline 0 & 78 & 70 & 65 & 1,55 & 1,65 & 1,438 \\
\hline 2,5 & 83 & 73 & 75 & 1,635 & 1,793 & 1,523 \\
\hline 5 & 75 & 73 & 70 & 1,425 & 1,758 & 1,693 \\
\hline 10 & 78 & 75 & 75 & 1,413 & 1,753 & 1,713 \\
\hline$F_{\text {tratamentos }}$ & $2,000^{\mathrm{ns}}$ & $0,308^{\mathrm{ns}}$ & 1,571 & $1,566^{\mathrm{ns}}$ & $0,284^{\mathrm{ns}}$ & $0,534^{\mathrm{ns}}$ \\
\hline $\mathrm{CV}(\%)$ & 9,59 & 15,46 & 16,04 & 0,36 & 0,48 & 0,77 \\
\hline d.m.s & 5,8 & 10,15 & 10,72 & 11,28 & 13,25 & 22,93 \\
\hline
\end{tabular}

${ }^{\text {ns }}$ não significativo. 


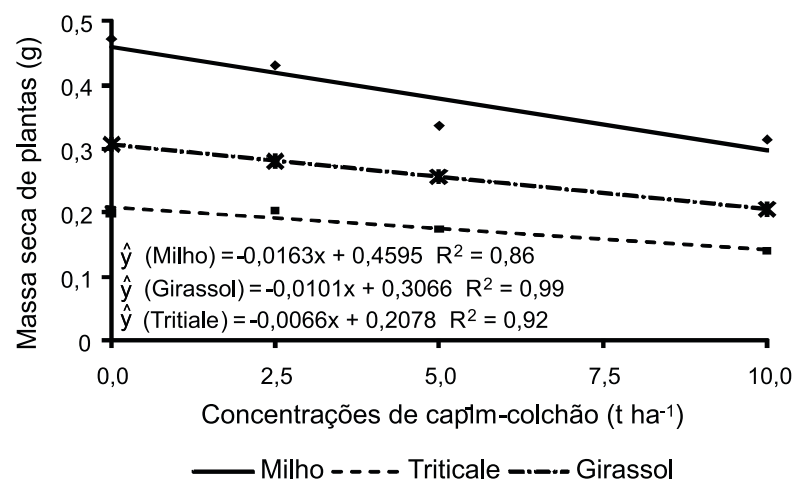

Figura 1 - Massa seca de plantas (g) de milho, triticale e girassol cultivadas em solo com diferentes concentrações de massa seca de capim-colchão. Botucatu-SP, 2009.

Os resultados de altura do experimento com plantas de milho e girassol foram um indicativo do potencial inibitório do capimcolchão sobre essas espécies, que reduziu em 26,5 e $14,6 \%$ a altura de plantas no solo com $10 \mathrm{t} \mathrm{ha}^{-1}$ de palhada, o que é corroborado por dados de Tokura \& Nóbrega (2005), que observaram redução do comprimento da parte aérea de plântulas de milho sob influência de extratos de colza, milheto e aveia. Contudo, não foi observada influência com o uso de extrato de nabo. A redução da altura de plantas com a utilização de 2,5 e $5,0 \mathrm{t} \mathrm{ha}^{-1}$ foi menor, sendo de 3,8 e $11,1 \%$ nas plantas de milho e de 7,9 e $9,3 \%$ nas de girassol, respectivamente. A redução da massa seca e da altura foram tanto maior quanto maior a concentração de palhada incorporada ao solo.

O potencial alelopático das plantas depende do grau de composição do resíduo vegetal, da liberação dos seus compostos químicos e de suas interações com o solo utilizado. Dessa forma, o contato das raízes, que são altamente eficientes na absorção, com os compostos liberados pela palhada de capim-colchão pode ter ocasionado maior efeito delas sobre as culturas.

Diante do exposto, pode-se inferir que a incorporação da palhada de capim-colchão não interferiu na germinação e no IVE das espécies avaliadas. Já a massa seca e a altura de plantas de todas as espécies foram influenciadas, decrescendo de acordo com o aumento da concentração da palhada incorporada ao

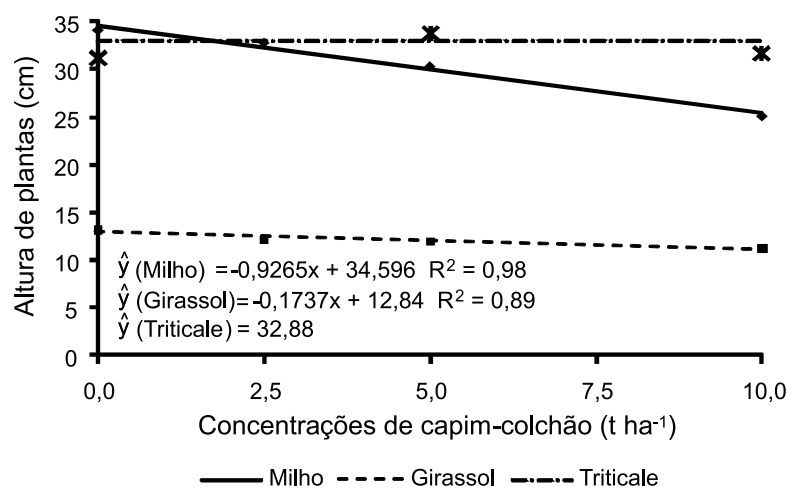

Figura 2 - Altura média de plantas (cm) de milho, triticale e girassol cultivadas em solo com diferentes concentrações de massa seca de capim-colchão. Botucatu-SP, 2009.

solo, com exceção do triticale, o qual não teve sua altura influenciada.

\section{LITERATURA CITADA}

ALMEIDA, F. S. Efeitos alelopáticos de resíduos vegetais. Pesq. Agropec. Bras., v. 26, n. 2, p. 221-236, 1991

ANDRADE, H. M.; BITTENCOURT, A. H. C.; VESTENA, $\mathrm{S}$. Potencial alelopático de Cyperus rotundus $\mathrm{L}$. sobre espécies cultivadas. Ci. Agrotec., v. 33, p. 1984-1990, 2009. (Edição Especial)

CHIAPUSO, G. et al. Do germination indices adequately reflect allelochemical effects on the germination process. J. Chem. Ecol., v. 23, p. 2445-2453, 1997.

CORREIA, N. M.; CENTURION, M. A. P. C.; ALVES, P. L. C. A. Influência de extratos aquosos de sorgo sobre a germinação e o desenvolvimento de plântulas de soja.

Ci. Rural, v. 35, n. 3, p. 498-503, 2005.

\section{EMPRESA BRASILEIRA DE PESQUISA}

AGROPECUÁRIA. Centro nacional de pesquisa de solos. Sistema brasileiro de classificação de solos. Rio de Janeiro: 1999. 412 p.

FERREIRA, A. G.; AQUILA, M. E. A. Alelopatia, uma área emergente da ecofisiologia. R. Bras. Fisiol. Veg., v. 12, p. 175-204, 2000.

GOLDFARB, M.; PIMENTEL, L. W.; PIMENTEL, N. W. Alelopatia: relações nos agroecossistemas. Tecnol. Ci. Agropec., v. 3, n. 1, p. 23-28, 2009

HALL, M. H.; HENDERLONG, P. R. Alfafa autotoxic fraction characterization and initial separation. Crop Sci., v. 29, n. 2 , p. $425-428,1989$. 
ISFAHAN, M. N.; SHARIATI, M. The effect of some allelochemicals on seed germination of Coronilla varia $\mathrm{L}$. seeds Am. J. Agric. Environ. Sci., v. 2, n. 5, p. 534-538, 2007.

MACIEL, C. D. G. et al. Influência do manejo da palhada de capim-braquiária (Brachiaria decumbens) sobre o desenvolvimento inicial de soja (Glycine max) e amendoimbravo (Euphorbia heterophylla). Planta Daninha, v. 21, n. 3, p. 365-373, 2003.

MIRÓ, C. P.; FERREIRAA. G.; AQUILA M. E. Alelopatia de frutos de erva-mate (Ilex paraguariensis) no desenvolvimento do milho. Pesq. Agropec. Bras., v. 33, n. 8, p. $1261-1270,1998$

NUÑEZ, L. A. et al. Allelochemical stress causes inhibition of growth and oxidative damage in Lycopersicon esculentum Mill. Plant Cell Environ., v. 29, n. 11, p. 2009-2016, 2006

OLIBONE, D. et al. Crescimento inicial da soja sob o efeito de resíduos de sorgo. Planta Daninha, v. 24, n. 2 , p. 255-261, 2006.

ORACZ, K. et al. Induction of oxidative stress by sunflower phytotoxins in germinating mustard seeds. J. Chem. Ecol., v. 33, n. 2 , p. $251-264,2007$
PRATES, H. T.; PIRES, N. M.; PEREIRA FILHO, I. A. Controle de plantas daninhas na cultura do milho utilizando leucena (Leucena leucocephala (Lam.) de Wit). R. Bras. Milho Sorgo, v. 2, n. 2, p. 36-43, 2003.

PUTNAM, A. R.; TANG, C. S. The science of allelopathy. Crop Protec., v. 6, n. 6, p. 410-411, 1987.

RAIJ, B. van. et al. Recomendações de adubação e calagem para o Estado de São Paulo. 2.ed. Campinas: Instituto Agronômico/Fundação IAC, 1997. 285 p. (Boletim Técnico, 100)

SOUZA FILHO, A. P. S.; RODRIGUES, L. R. A.; RODRIGUES, T. J. D. Potencial alelopático de forrageiras tropicais: efeitos sobre invasoras de pastagens

Planta Daninha, v. 15, n. 1, p. 53-60, 1997.

TOKURA, L. K.; NÓBREGA, L. H. P. Potencial alelopático no desenvolvimento de milho. Acta Sci. Agron., v. 27, n. 2, p. 287-292, 2005.

WEIR, T. L; PARK, S. W.; VIVANCO, J. M. Biochemical and physiological mechanisms mediated by allelochemicals. Curr. Opin. Plant Biol., v. 7, n. 4, p. 472-479, 2004. 